\title{
Current perspectives on fetal and neonatal alloimmune thrombocytopenia - increasing clinical concerns and new treatment opportunities
}

This article was published in the following Dove Press journal:

International Journal of Women's Health

19 April 2017

Number of times this article has been viewed

\author{
Heidi Tiller' \\ Anne Husebekk' \\ Maria Therese Ahlen² \\ Tor B Stuge' \\ Bjørn Skogen ${ }^{3}$ \\ 'Immunology Research Group, \\ Faculty of Health Sciences, UiT, \\ The Arctic University of Norway, \\ ${ }^{2}$ Division of Diagnostic Services, \\ Department of Laboratory Medicine, \\ ${ }^{3}$ Department of Laboratory Medicine, \\ Norwegian National Unit for Platelet \\ Immunology, University Hospital of \\ North Norway, Tromsø, Norway
}

Correspondence: Heidi Tiller Department of Obstetrics and Gynecology, University Hospital of North Norway, Breivika, 9038 Tromsø, Norway Tel +479707 8098

Email heidi.tiller@unn.no

\begin{abstract}
Differences in platelet type between the fetus and the mother can lead to maternal immunization and destruction of the fetal platelets, a condition named fetal and neonatal alloimmune thrombocytopenia (FNAIT). FNAIT is reported to occur in $\sim 1$ per 1,000 live born neonates. The major risk is intracranial hemorrhage in the fetus or newborn, which is associated with severe neurological complications or death. Since no countries have yet implemented a screening program to detect pregnancies at risk, the diagnosis is typically established after the birth of a child with symptoms. Reports on broader clinical impact have increased clinical concern and awareness. Along with new treatment options for FNAIT, the debate around antenatal screening to detect pregnancies at risk of FNAIT has been revitalized.
\end{abstract}

Keywords: antibodies, screening, alloimmunization, platelets, newborn, pregnancy

\section{Introduction}

Fetal and neonatal alloimmune thrombocytopenia (FNAIT) is not a common pregnancy complication but carries a significant risk of severe fetal and/or neonatal complications and has been recognized as the major cause of primary hemorrhagic morbidity and mortality in fetuses and newborns. ${ }^{1}$ In neonatal intensive care units, severe thrombocytopenia (platelet count $<50 \times 10^{9} / \mathrm{L}$ ) is reported in $5 \%-22 \%$ of children., ${ }^{2,3}$ Most of these cases have underlying causes such as prematurity, congenital infections, maternal immune thrombocytopenic purpura, or chronic fetal hypoxia. ${ }^{3,4}$ However, in otherwise healthy term newborns with isolated severe thrombocytopenia, the most frequent cause is FNAIT. ${ }^{5-7}$ The condition occurs in $\sim 1$ per 1,000 births in Caucasian populations. ${ }^{7}$

The aim of this review was to give an overview of FNAIT, with a focus on recent developments in its clinical aspects and treatment options.

\section{Pathogenesis}

The fetus is semiallogeneic by nature, but generally well tolerated by the maternal immune system. However, some polymorphisms can cause maternal alloimmunization in incompatible pregnancies - resulting in maternal antibodies that target fetal cells for destruction. The clinical manifestations of the conditions depend on the target for the maternal alloantibodies. The most classic immune response in incompatible pregnancies is immune response to $\mathrm{RhD}$ antigens on fetal red cells. Red cell alloimmunization can cause hemolytic disease of the fetus or newborn (HDFN). Fetomaternal incompatibility for human neutrophil antigens may induce antibodies targeting neutrophils causing neonatal neutropenia making the newborn 
susceptible for infections. Incompatibility for human platelet antigens (HPAs) can induce antibodies against fetal platelets, which may lead to FNAIT and hemorrhagic complications. FNAIT is defined as fetal or neonatal thrombocytopenia caused by antibodies targeting alloantigens on fetal platelets (from now on referred to as alloantibodies) because of incompatibility between fetal and maternal platelet antigens.

Maternal antiplatelet immunoglobulins (IgG) are transported across the placenta (mostly $\operatorname{IgG}_{1}$ and $\operatorname{IgG}_{3}$ ) to the fetal blood system, primarily by the major histocompatibility complex (MHC)-class I-related neonatal Fc receptor. ${ }^{8}$ These antibodies will bind to the fetal platelets, and the platelets will subsequently be removed from the fetal circulation by phagocytosis.

The HPAs are located on platelet membrane glycoprotein receptors. These glycoproteins play fundamental roles in platelet functions, such as adhesion and aggregation. Most HPAs are based on single-nucleotide polymorphisms resulting in amino acid substitutions localized on the main platelet receptors: integrin $\alpha \mathrm{IIb} \beta 3$ (GPIIb/IIIa, CD41/CD61: the fibrinogen receptor), the GPIb-IX-V complex (CD42, von Willebrand factor receptor), and the GPIa/IIa complex ( $\alpha 2 \beta 1, \mathrm{CD} 29$, the collagen receptor). ${ }^{9}, 10$ HPA-15 is the only exception; this biallelic system is carried by the platelet membrane protein $\mathrm{CD} 109,{ }^{11}$ which is a part of the transforming growth factor- $\beta$ receptor system. ${ }^{12}$ For a more comprehensive presentation of platelet membrane glycoproteins, the recent review by Zdravic et $\mathrm{al}^{13}$ is suggested.

Platelet-specific antigens were first described in the late 1950s and early 1960 s. ${ }^{14,15}$ To date, 35 different plateletspecific alloantigens have been described as targets for antibodies in FNAIT, of which 12 are grouped in six biallelic systems (HPA-1, -2, -3, -4, -5, and -15; http://www.ebi.ac.uk/ ipd/hpa/table1 [accessed September 2016]).

Antigen incompatibility in HPA-1 is found to cause $80 \%-90 \%$ of FNAIT cases in the Caucasian population. ${ }^{16-18}$ The HPA- 1 antigen is located on the integrin $\beta 3$, defined by a Leu33Pro polymorphism in the PSI domain. Carriers of the Leu33 allelic variant are defined as HPA-1a positive, whereas those who carry homozygous Pro33 alleles are termed HPA-1 a negative or HPA-1bb. The classic HPA-1a antigen is a part of the integrin $\alpha \operatorname{IIb} \beta 3$ complex, also known as the fibrinogen receptor, which is restricted to platelets and megakaryocytes. However, the integrin $\beta 3$ subunit of the fibrinogen receptor is also part of the integrin $\alpha V \beta 3$ complex (vitronectin receptor), which is expressed on other fetal cells, including angiogenic endothelial cells and invasive trophoblasts. ${ }^{19,20}$

Fetal megakaryocytes - the precursors of platelets - are found in lung and liver as early as in the 12th gestational week. Platelet counts in the healthy fetus are within normal adult range no later than 18 th gestational weeks..$^{21,22}$ Fetal platelet antigens are expressed in normal amounts as early as week $16 .{ }^{20}$ Maternal IgG alloantibodies from previous pregnancies are detectable in fetal blood from gestational week $6^{23}$ and start to increase from early in the second trimester. ${ }^{23,24}$ Fetal thrombocytopenia caused by maternal alloantibodies may therefore occur very early during pregnancy.

The immune response against HPA-1a is strongly associated with the human MHC class II allele $H L A$ $D R B 3 * 01: 01 .{ }^{25-29}$ In the Norwegian screening study, $90 \%$ of HPA-1a immunized women were $D R B 3^{*} 01: 01$ positive. ${ }^{25}$ In comparison, $28 \%$ of a random population were $D R B 3 * 01: 01$ positive. ${ }^{26}$ This strong association suggests that CD4 T-cell activation by the DRA/DRB3*01:01 molecule is a determining event in the immune response against HPA-1a. In support of this notion, it has been shown that integrin $\beta 3$-derived peptides with Leu33 (HPA-1a peptide), but not with Pro33, bind well to the DRA/DRB3*01:01 molecule and thus can be presented by antigen-presenting cells. ${ }^{30,31}$ Also, HPA-1aspecific DRA/DRB3*01:01-restricted CD4 T cells have been isolated from women who have had a child affected by FNAIT ${ }^{32,33}$ Predictably, DRA/DRB3*01:01-restricted HPA-1a-specific CD4 $\mathrm{T}$ cells provide essential help to HPA-1a-specific B cells to differentiate to anti-HPA-1a antibody producing plasma cells. Leu 33 has been shown to serve as an anchor residue for stable binding of HPA-1a peptide to the DRA/DRB3*01:01 molecule ${ }^{31}$ and is not solvent exposed. T-cell recognition of the allogeneic leu33 residue is therefore indirect. ${ }^{34}$

Despite large efforts, we still do not completely understand what makes some HPA-1bb women prone to alloimmunization; most are not immunized in connection with an HPA-1 incompatible pregnancy. A recent observation by Li et $\mathrm{al}^{35}$ that infection status in the mother may play a role is interesting and implies that a proinflammatory event trigger the alloimmune response. However, we should also focus on understanding the mechanisms that induce immune tolerance, which could have an important role in preventing most women from becoming alloimmunized.

The clinical relevance of different anti-HPA antibodies varies among different ethnic groups. In a Caucasian population, anti-HPA-1a antibodies are by far the most common and clinically relevant cause of FNAIT. ${ }^{17,18,36}$ Approximately 
$2 \%$ of Caucasian women are HPA-1a negative and at risk of being immunized in connection with an HPA-1 incompatible pregnancy. ${ }^{25,37}$ The frequency of FNAIT due to antiHPA-1a antibodies is reported to be $1: 1,100$ live births. ${ }^{18,25,38}$ An overview of the pathophysiology of maternal HPA-1 alloimmunization is shown in Figure 1.

In addition, anti-HPA-5b antibodies cause FNAIT in $7 \%-16 \%$ and anti-HPA- $15 \mathrm{~b}$ in $2 \%-4 \%$ of the cases. ${ }^{16,17,36,39}$ The African-American population seems to have a lower incidence of anti-HPA-1a-induced FNAIT but have higher risk of alloimmunization to HPA-2 and HPA-5 antigens. ${ }^{40}$ Among Japanese, HPA-4 and HPA-5 alloimmunizations are most frequent. ${ }^{41,42}$

The human leukocyte antigen class I (HLA class I) is present on all nucleated cells and platelets in the human body. The genes that encode HLA class I are the most polymorphic in the human genome. Exposure to non-self-HLA can activate the host immune system and lead to the production of alloantibodies. It is well known that anti-HLA class I antibodies can have severe clinical consequences, such as rejection of allografts $\mathrm{s}^{43,44}$ or destruction of transfused platelets. ${ }^{45}$ Maternal anti-HLA class I antibodies are detected during pregnancy in at least $30 \%$ of multigravida. ${ }^{46-49}$ Although these antibodies have been reported in association with various pregnancy complications,

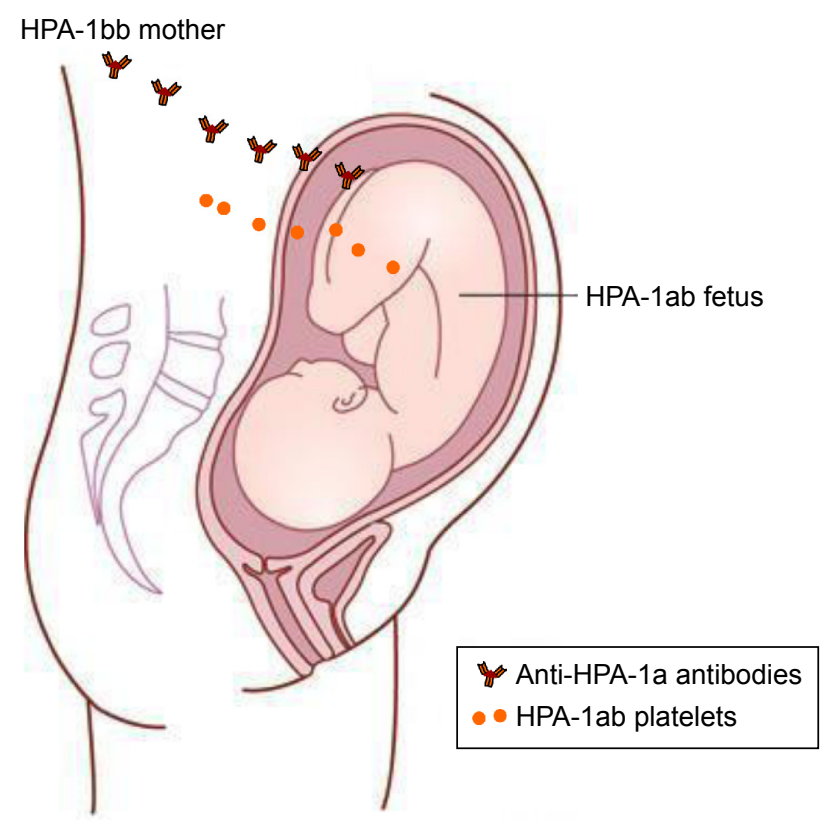

Figure I Pathophysiology of maternal HPA-I alloimmunization.

Notes: In an HPA-Ibb mother who is pregnant with an HPA-lab fetus, fetal platelets/fetal platelet antigen may enter the maternal circulation and lead to the production of anti-HPA-la antibodies in the mother. Copyright (C) 2003. The Norwegian Medical Association. Reproduced from Heier HE, Berge LN, Hervig T, et al. Immunisering i svangerskapet. [Immunization during pregnancy]. Tidsskr Nor Laegeforen. 2009; I 29(19):2016-2018. ${ }^{137}$

Abbreviation: HPA, human platelet antigen. the possible harmful effects on pregnancy are still not clear. ${ }^{50}$ Numerous reports describe suspected cases of FNAIT with maternal anti-HLA class I antibodies as the only finding and possible explanation of neonatal thrombocytopenia. ${ }^{51-55}$ It has therefore been suggested that maternal anti-HLA class I antibodies may cause FNAIT, but this is still controversial. ${ }^{46,56}$

\section{Diagnosis}

The diagnosis of FNAIT requires that the fetus/neonate carries a platelet alloantigen that the mother lacks, and to which she has made detectable antibodies. ${ }^{57}$ The current gold standard for the detection of platelet-specific antibodies is the monoclonal antibody-specific immobilization of platelet antigen (MAIPA) assay, ${ }^{58}$ a sensitive and specific ${ }^{59,60}$ capture immunoassay. Quantitation of anti-HPA-1a antibodies is done using a modified MAIPA assay. ${ }^{61}$ Other HPA alloantibody specificities are normally not quantified. Other techniques are also possible to use. For instance, different Luminex bead-based assays for the detection of anti-HPA-1a antibodies have been tested and are used by some. ${ }^{62}$ Furthermore, low-avidity anti-HPA-1a antibodies may be detected using surface plasmon resonance technology. ${ }^{63}$

Cordocentesis has been used in order to identify thrombocytopenic fetuses requiring intrauterine platelet transfusions and also to help decide on antenatal maternal treatment. Because of high risk of procedure-related complications, ${ }^{64}$ avoidance of invasive procedures is currently recommended. ${ }^{4,65-67}$

Assays for noninvasive prenatal testing to detect fetal HPA-1a DNA in maternal plasma have been developed and are in use in many research laboratories, but are not yet implemented in routine clinical practice in most countries. ${ }^{6-72}$ Determination of paternal zygosity may be relevant. If the father is typed and found to be HPA-1aa, the pregnancy will always be HPA-1 incompatible and fetal HPA-1 genotyping is not necessary. Whereas if the father is HPA-1ab, there is a $50 \%$ chance of the fetus being HPA-1bb and compatible with the mother, and in this situation knowing the fetal HPA-1 genotype would be clinically helpful.

\section{Clinical presentation and outcome Neonatal thrombocytopenia}

The suspicion of FNAIT is typically raised when a newborn develops widespread skin petechiae shortly after birth and blood tests show severe thrombocytopenia. Most FNAIT cases present with platelet counts well below $50 \times 10^{9} / \mathrm{L}^{25,39,73}$ Clinical symptoms range from no symptoms to limited or widespread skin petechiae or purpura to symptoms of 
extra- or intracranial hemorrhage (ICH). Baseline characteristics of HPA-1-induced FNAIT are shown in Figure 2.

\section{Intracranial hemorrhage}

ICH is the major reason for clinical concern in FNAIT. ICH due to FNAIT is reported to occur in 1 of 10,000 births. $^{\text {? }}$ A recent review of prospective screening and intervention studies reported ICH in 7\% of severe FNAIT cases (neonatal platelet count $\left.<50 \times 10^{9} / \mathrm{L}\right) \cdot{ }^{37}$ Retrospective studies report a frequency of ICH due to FNAIT in $13 \%-21 \%$ of severe cases. ${ }^{17,39,74}$ The clinical outcome of ICH due to FNAIT is reported to be worse compared to neonatal ICH from other causes $^{75,76}$ and may be connected to the typical locations of the bleedings in the brain. Severe neurological complications are found in $36 \%-68 \%$ of ICH cases $^{24,26,77,78}$ and fetal or neonatal death due to $\mathrm{ICH}$ is reported in the range of $9 \%-46 \% 0^{24,57,68,79}$ when evaluated retrospectively. A large cohort study from the international No Intracranial Hemorrhage (NOICH) registry described 43 cases of ICH caused by FNAIT in depth and found that the majority of bleedings (54\%) happened before the third trimester and $67 \%$ before 34 gestational weeks. ${ }^{77}$ Similar results were recently published for a French cohort of ICH cases caused by FNAIT, ${ }^{79}$ and a recent systematic review on clinical consequences of neonatal alloimmune thrombocytopenia also describes this tendency. ${ }^{7}$ Results from the NOICH registry further indicated that boys may be more prone to bleeding compared with girls. ${ }^{77}$

The majority of ICH cases are reported to occur in the first-born child. ${ }^{77}$ Thus, in most of the reported cases of ICH, antenatal treatment was not given since the risk of FNAIT typically was not known. The recurrence rate of ICH in

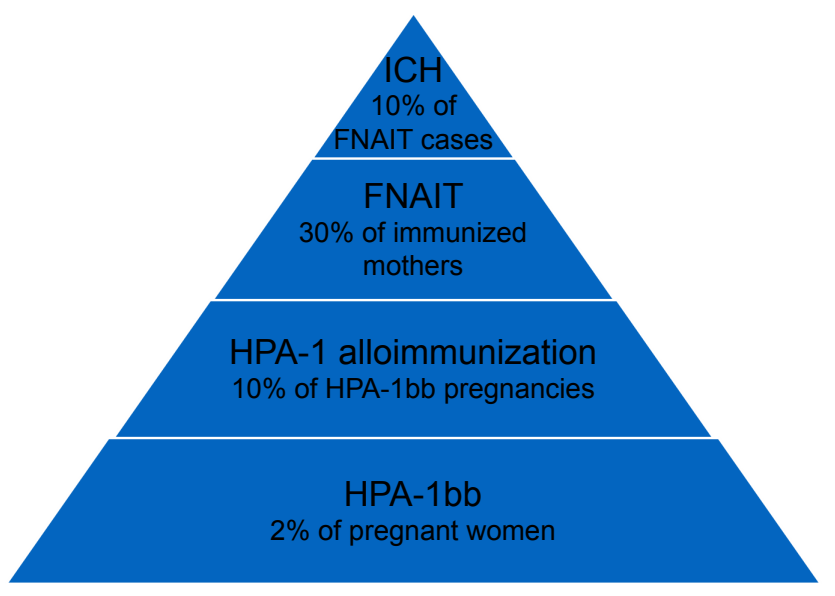

Figure 2 Baseline characteristics of HPA-I-induced fetal and neonatal alloimmune thrombocytopenia.

Abbreviations: ICH, intracranial hemorrhage; FNAIT, fetal and neonatal alloimmune thrombocytopenia; HPA, human platelet antigen. subsequent pregnancies is reported to be $79 \%{ }^{64}$ If the index FNAIT child did not have ICH, the risk of ICH in the next pregnancy has been estimated at $7 \%{ }^{64}$

Intrauterine fetal death (IUFD) is sometimes reported as an FNAIT complication separate from ICH, but there are no data to indicate that the cause of FNAIT-related IUFD should be something else than ICH. Therefore, IUFD will not be discussed separately.

\section{Extracranial hemorrhage}

FNAIT may lead to severe bleeding other than ICH in neonates with FNAIT. In the recent overview of extracranial FNAIT hemorrhage by Winkelhorst et al, ${ }^{80}$ a wide variety of bleeding complications were reported in the 21 cases identified. Gastrointestinal bleedings constituted the majority of cases, followed by pulmonary hemorrhage. Some of these bleedings were life-threatening, and therefore, it is important for clinicians to be aware of possible extracranial bleedings in the fetus or neonate when managing an HPA-alloimmunized pregnancy or caring for a neonate with severe FNAIT.

\section{Miscarriage}

Mothers of FNAIT-affected children often report a history of miscarriages, including second trimester miscarriages, suggesting that the risk of miscarriage may be increased. ${ }^{81}$ In a murine model of FNAIT, it was found that maternal anti-integrin $\beta 3$ antibodies promoted fetal miscarriage, ${ }^{82,83}$ and recent data from the same group suggest that anti-integrin $\beta 3$ antibodies may activate placental natural killer cells leading to placenta damage and miscarriage through antibody dependent cellular cytotoxicity. ${ }^{84}$

Yet, no human study has specifically addressed whether there is an association between maternal HPA alloimmunization and miscarriage. Given the high prevalence of miscarriage in general and lack of understanding and treatment options for recurrent miscarriage, it is rather surprising that this area of pregnancy outcome for HPA alloimmunization has not received more attention.

\section{Placental function and birth weight}

Normal placental function is vital for a successful and uncomplicated pregnancy. Placental development and function are primarily established during the first half of pregnancy, although its growth and maturation continues throughout the pregnancy. Defect placentation is a common denominator for the "great obstetric syndromes" - preeclampsia, intrauterine death, and fetal growth restriction. Growth restricted fetuses/low birth weight newborns have increased risk of disease and death in the 
newborn period, as well as in adulthood. ${ }^{85-87}$ How mother and fetus co-exist and "negotiate" to achieve normal placentation is complex and not yet fully understood.

We previously found a strong association between the presence of maternal anti-HPA-1a antibodies and reduced birth weight in boys. ${ }^{88} \mathrm{~A}$ similar observation was made in an international multicenter study, showing that $23 \%$ of neonates with $\mathrm{ICH}$ were below the 10th percentile for birth weight and defined as small for gestational age. ${ }^{77}$ Recently, we also found a similar association between the presence of maternal anti-HLA class I antibodies and reduced birth weight in cases where the child was thrombocytopenic at birth, and in this work, we also observed concurrently lower placental weight. ${ }^{89}$

HPA-1 antigens are expressed on the surface of fetal invading trophoblasts as part of the vitronectin receptor, and we know that anti-HPA-1a antibodies can bind the HPA-1a antigen when present on the vitronectin receptor. ${ }^{90,91}$ The vitronectin receptor promotes cell adhesion and migration of primary cytotrophoblasts. ${ }^{92,93}$ Recently, it was found that antiHPA-1a antibody affected adhesion, migration, and invasive capacity of extravillous throphoblasts using a first trimester trophoblast-derived cell line (HTR-8/SVneo), indicating that maternal anti-HPA-1a antibodies could lead to defect placentation, in turn leading to poor fetal growth (Eksteen et al, personal communication, January, 2017). Together with our previous observation that mothers with anti-HPA-1a antibodies give birth to children with lower birth weight, the findings of the present study indicate that anti-HPA-1a antibodies can interfere with placental development. The mechanisms linking FNAIT to placenta/birth weight are currently being explored.

\section{Predictors of clinical outcome}

Several studies have demonstrated an association between anti-HPA-1a antibody levels in pregnancy and the severity of neonatal thrombocytopenia. ${ }^{94-96}$ In a former large prospective screening study in Norway, maternal anti-HPA-1a antibody levels $\geq 3 \mathrm{IU} / \mathrm{mL}$ during pregnancy was found to be highly sensitive $(>90 \%)$ in predicting severe neonatal thrombocytopenia, ${ }^{96}$ and this level is currently used as cut-off in the national clinical guidelines to decide on delivery mode and place (www.legeforeningen.no). Some retrospective studies did not find such a relationship. ${ }^{97,98}$ These discrepant results have been discussed, and it was suggested that quantitation of maternal anti-HPA-1a antibody level by MAIPA can be useful in a screening setting but maybe not in cases where FNAIT was already diagnosed in a previous pregnancy. ${ }^{99}$ This explanation makes sense; when monitoring a risk pregnancy where a previous child had severe FNAIT, the obstetric history alone has strong predictive value. Furthermore, the anti-HPA-1a antibody level range is typically limited to very high levels in many such cases and statistical models aiming to study antibody level as a continuous variable will therefore fail to demonstrate significant associations.

A retrospective study reported that maternal antiHPA-1a antibody levels may be used as a prognostic factor of intravenous immunoglobulin (IVIg) therapy success or failure. ${ }^{100}$ This study was criticized for several weaknesses, ${ }^{101}$ but the possibility of using anti-HPA-1a antibody levels to decide on antenatal management and delivery is important and deserves more attention. The ongoing Polish FNAIT screening study Prevention of FNAIT in Polish Newborns (PREVFNAIT; http://www.konfliktplytkowy.ihit.waw.pl/en/) will therefore give us valuable data on 1) the effect of antenatal IVIg in a screening setting and 2) whether maternal anti-HPA-1a antibody levels during pregnancy is useful to evaluate a possible IVIg effect.

For decades, the "FNAIT paradigm" has been that maternal anti-HPA-1a antibodies cause destruction of fetal platelets and that it is the low number of platelets in the fetus/newborn that trigger bleeding. Questioning this paradigm, we recently learned that anti-HPA-1a antibodies can bind cerebral endothelium carrying the vitronectin receptor and exert a direct negative effect that may cause $\mathrm{ICH}$, bypassing the role of low platelet number alone as the main trigger for ICH. ${ }^{102}$ This strengthens the importance of using antibody levels instead of fetal platelet counts as tools in management planning. Following up on this, the most recent FNAIT research reported that in children with $\mathrm{ICH}$ caused by FNAIT, anti-HPA-1a antibodies in the mother targeted the vitronectin receptor $(\alpha v \beta 3)$, whereas maternal sera from FNAIT cases where the fetus/neonate did not have ICH had mainly antibodies binding the fibrinogen receptor $(\alpha \operatorname{IIb} \beta 3) .{ }^{103}$ Therefore, it will be important for future FNAIT research to differentiate between anti-HPA-1a antibodies binding to the fibrinogen receptor on platelets and antibodies binding to both the fibrinogen and the vitronectin receptors. These results need to be confirmed and explored further, but fit well with the current understanding of a direct antibody-mediated effect on vessel wall integrity and trophoblast functions.

Maternal anti-HPA-1a antibody levels in pregnancies where the fetus/neonate has $\mathrm{ICH}$ are reported to be very high compared with severe FNAIT cases without detectable $\mathrm{ICH} .{ }^{77,79}$ However, we do not yet have good prospective data 
to determine whether maternal anti-HPA-1a antibody levels during pregnancy may be useful as an additional predictive factor for the risk of ICH.

The composition and heterogeneity of the terminal sugars of the Fc portion of IgG antibodies can affect the effector functions of the antibody, and certain glycosylation patterns are known to play a role as disease biomarker. Two research groups recently described decreased fucosylation of antiHPA-1a antibodies causing FNAIT, and that fucosylation may be useful to predict disease severity. ${ }^{104,105}$

\section{Management}

\section{Intravenous immunoglobulin}

Previous severe FNAIT, with or without bleeding complications, is currently used clinically to determine the risk of severe FNAIT in subsequent pregnancies, and as such serves as the major basis in antenatal management planning. Weekly IVIg treatment to the mother starting from the second trimester is the first-line therapy of choice in most of the Western countries and is administered when the risk of FNAIT is considered to be high. ${ }^{4,67,106,107}$ The treatment is considered effective when the neonatal platelet count is increased or ICH avoided in a subsequent pregnancy compared with the previous FNAIT pregnancy, with the underlying assumption that FNAIT gets worse in younger siblings. In a recent Norwegian prospective study, the natural course of FNAIT in several subsequent pregnancies was reported for the first time. ${ }^{108}$ Our data showed that younger siblings of FNAIT-affected children had unchanged or higher neonatal platelet counts without antenatal treatment in the majority of subsequent pregnancies. Therefore, this study did not support the common opinion that the outcome after HPA-1a alloimmunization is generally worse in the next pregnancy. Thus, increased neonatal platelet count in a subsequent FNAIT pregnancy may not always reflect an antenatal treatment effect. Delbos et al reported that efficacy of IVIg treatment may be dependent on maternal HLA-DRB4*0101 haplotype, ${ }^{79}$ also suggesting the possible use of several HLA-DR haplotypes as predictive markers of clinical outcome.

In a review of maternal IVIg response, it was commented that despite controversy whether IVIg increases fetal platelet counts, all IVIg studies report identical low frequency of $\mathrm{ICH},{ }^{109}$ indicating that the possible effect of IVIg may be different from increased platelet count. Results from the NOICH study found that IVIg treatment during the subsequent pregnancy seemed to be protective with regard to $\mathrm{ICH}$ in most cases, reducing the $\mathrm{ICH}$ recurrence risk from $79 \%$ as previously reported to $11 \% .{ }^{77}$ In a murine model of FNAIT, it was demonstrated that treatment with IVIg to immunized mice prevented $\mathrm{ICH}$ in the pups, ${ }^{83}$ and the same group later published data suggesting that IVIg prevented ICH by restoring angiogenesis in the fetal brain. ${ }^{102}$

\section{Corticosteroids}

Some clinicians use systemic corticosteroids alongside IVIg as a means of supporting the action of IVIg. Dexamethasone is not recommended due to risk of oligohydramnios at higher doses ${ }^{110}$ and lack of effect at lower doses. ${ }^{111}$ Prednisone is therefore the recommended choice; however, the potential benefits versus risks deserves further evaluation. ${ }^{112}$

\section{Cordocentesis}

Repeat cordocentesis to measure fetal platelet count followed by intrauterine platelet transfusions in case of severe fetal thrombocytopenia was commonly performed previously, but is nowadays abandoned by many countries due to high risk of procedure-related complications. ${ }^{113,114}$ Some countries still combine diagnostic fetal blood sampling (FBS) with maternal IVIgs, with or without a second FBS to decide on treatment effect and mode of delivery. However, a complete noninvasive management strategy is advocated by most. ${ }^{65,67,115}$

\section{Pre-implantation genetic diagnosis}

When the mother is HPA-1bb and the father is HPA$1 \mathrm{ab}$, there is a $50 \%$ chance that the fetus will be HPA-1a positive. In cases of a previously FNAIT-affected sibling, some women are not eligible for antenatal IVIg treatment due to hypersensitivity. The possibility of performing preimplantation genetic diagnosis for HPA-1 incompatibility in order to select an HPA-1bb embryo for in vitro fertilization (IVF) has been described in a case report. ${ }^{116}$ This may be a desirable option for couples facing a similar situation.

\section{In vitro fertilization}

When the mother is HPA-1bb and the father is HPA-1aa, pre-implantation genetic diagnosis is not helpful, as the fetus will always be HPA-1ab. The use of HPA-1-matched sperm donor is a new procedure. The first woman in Norway to conceive after using an HPA-1-matched sperm donor delivered a healthy boy with normal platelet count in 2014. ${ }^{117}$ In Spring 2016, the second child was delivered using this treatment strategy, and this pregnancy also underwent without complications and a healthy newborn with normal platelet count was born by caesarean section (Dr Peter Fedorscak, Oslo University Hospital, personal communication, May 2016). Needless to 
say, more experience with this treatment option is needed before introducing this as part of a general management program. Because of the ethical challenges, we would generally recommend to consider the use of HPA-1-matched sperm donor only for the minority of HPA-1bb women with a history of recurrent severe FNAIT-related complications, where the alternative would be to refrain from further pregnancies.

HPA-1 typing is not routinely performed in connection with the use of IVF. IVF was reported to be involved in four severe cases of anti-HPA-1a-induced FNAIT. ${ }^{118}$ In three out of the four cases, the fetuses were HPA-1aa homozygous, which could not occur in naturally conceived HPA-1 incompatible pregnancy. In these cases, either the surrogate or mother was HPA-1bb homozygous. The authors speculate that a homozygous HPA-1a fetus express twice as much incompatible antigen on their platelets, inducing a stronger maternal immune response. Alternatively, the severity could be due to antibody binding to all fibrinogen receptors on fetal platelets; only half of the receptors can be bound on platelets in HPA-1 ab individuals, leaving platelets partially functional. Anti-HPA-1a antibodies affect HPA-1aa platelet function more than HPA-1ab. ${ }^{90}$ This finding needs to be confirmed or disproved by others. However, their conclusion that all women should be HPA-1 genotyped before serving as a surrogate mother seems feasible and deserves attention in view of the rapidly increased use of surrogacy.

\section{Mode of delivery}

Whether delivery by caesarean section prevents ICH in FNAIT affected neonates is not really known. ${ }^{37,119}$ Vaginal delivery is advised by some as an option when fetal platelet count is $>50 \times 10^{9} / \mathrm{L} .{ }^{111}$ However, this approach requires FBS in order to know the fetal platelet count around the time of delivery. A Dutch pilot study of 32 pregnancies where an older sibling had FNAIT without ICH found that vaginal delivery was not associated with an increased risk of ICH. ${ }^{120}$ The current policy in the Netherlands is to induce vaginal delivery at 37-38 weeks without FBS first. If the woman has a previous caesarean section, they may sometimes do a FBS before inducing delivery. If the previous child had $\mathrm{ICH}$, delivery is performed by elective caesarean section at 36 weeks (prof Dick Oepkes, Director of the Dutch National Centre for Fetal Therapy, Leiden University Medical Centre in the Netherlands, personal communication, March, 2016). The intervention part of the Norwegian screening study consisted of delivering all HPA-1a alloimmunized women by caesarean section at 36-38 weeks followed by immediate transfusion of HPA-1 compatible platelets if the newborn was severely thrombocytopenic..$^{25}$ Delivery by caesarean section was one of several interventions in this study, and the isolated effect of delivery mode is therefore difficult to assess. Still, mortality and morbidity were significantly reduced in the screening and intervention population compared with historical controls. ${ }^{29}$ The current management guideline in Norway recommends delivery by elective caesarean section around 38 weeks if the maternal anti-HPA-1 a antibody level is $\geq 3 \mathrm{IU} / \mathrm{mL}$, irrelevant of previous obstetric history.

Since the vast majority of ICH caused by FNAIT is found to occur before delivery, and little data support the idea that ICH due to FNAIT tend to occur in connection with delivery, it is difficult to argue that the risk of ICH is affected by mode of delivery. The risk of ICH when older siblings did not suffer from $\mathrm{ICH}$ is reported to be $7 \% .{ }^{57}$ A larger study sample is therefore needed before we can conclude whether vaginal delivery for this patient group is safe or not. In many places, HPA-1bb platelets are not available in the blood banks on a daily basis. A planned delivery - whether vaginally or by surgery - is therefore important in order to have appropriate platelets available in case of a severely thrombocytopenic newborn.

\section{Postnatal management of the newborn}

The majority of FNAIT-affected newborns will not have suffered ICH before delivery. Preventing ICH by increasing platelet count above a certain threshold is therefore considered a neonatal emergency, and prompt correction by platelet transfusion should be done based on clinical suspicion without awaiting laboratory confirmation of the diagnosis. ${ }^{4}$ However, it is not clear what threshold should be used to trigger platelet transfusion. ${ }^{121,122}$ Previous reports also suggest that neonates with HPA-5b incompatibility may be at risk of bleeding at higher platelet counts compared with HPA-1 incompatibility. ${ }^{39}$ It is recommended to give compatible platelet concentrates instead of random donor platelets, due to both larger platelet increment and longer half-life of the transfused platelets. ${ }^{123,124}$ Random donor platelets may be used when compatible platelets are not available. ${ }^{123}$ The use of IVIg as treatment to increase neonatal platelet count varies, but is often recommended as supplemental therapy for 1-3 days depending on platelet increment response of transfusions. ${ }^{106,107,122,124}$ Other management options include corticosteroid therapy, but documentation of effect is poor. ${ }^{125}$ It is also recommended that all babies with severe FNAIT should have a cranial ultrasound for the detection of $\mathrm{ICH} .{ }^{122}$

In summary, there is consensus on postnatal correction of severe thrombocytopenia, but antenatal treatment management 
protocols vary. Knowledge gaps on the natural history of FNAIT, together with lack of randomized controlled trials evaluating the effects of different treatment options, are probably a major reason for the struggle to have common management protocols. Still, nobody questions the severity of this disorder. Therefore, there is no doubt that a preventive approach hindering the mother from becoming HPA-1a alloimmunized in the first place would be welcomed by all.

\section{A prophylactic approach to FNAIT}

FNAIT is often referred to as the platelet counterpart of HDFN, but traditionally presented with one important exception - time of immunization. Alloimmunization against the $\mathrm{RhD}$ antigen mainly occurs in connection with delivery as a result of fetomaternal hemorrhage. ${ }^{126,127}$ Until recently, it was believed that most immunizations to HPA-1a occurred during the first incompatible pregnancy and not so often in connection with delivery. This assumption was based on retrospective observations. Now, data from several prospective investigations have challenged this belief. In the Norwegian screening study, it was found that $>75 \%$ of HPA-1a alloimmunizations occurred after delivery, suggesting that delivery may be the immunizing stimulus. ${ }^{96}$ Similar prospective data were also presented by Turner et $\mathrm{al}^{73}$ and Williamson et al, ${ }^{18}$ reporting a low frequency of immunizations during first pregnancies ( $4 \%$ and $24 \%$, respectively). Thus, the pathophysiology of FNAIT seems to be more similar to HDFN than previously thought. This recognition has opened the possibility to prevent anti-HPA-1a-induced FNAIT by postnatal administration of HPA-1a antibodies to HPA-1anegative women delivering an HPA-1a-positive child. This is actually the same strategy that has been used to prevent HDFN with great success during the past 50 years. In order to test this hypothesis, a proof-of-principle study using glycoprotein integrin $\beta 3$ (GPIIIa)-deficient mice was conducted. Administration of human polyclonal anti-HPA-1a or murine monoclonal anti-HPA-1a (clone SZ21) were both able to suppress the antibody response to transfused human HPA-1apositive platelets. The induction of antibody-mediated immune suppression was also carried out using murine wild-type platelets transfused to GPIIIa-deficient mice. The antibody response to platelets was significantly reduced in mice receiving anti-GPIIIa in conjunction with platelet transfusion. Breeding experiments further demonstrated that the platelet count in the pups born by the mice that had received prophylaxis after the platelet transfusion was significantly higher compared to controls where the mother did not receive prophylactic treatment. The number of pregnancies with miscarriages and dead pups was also significantly lower when the platelet transfusion was followed by prophylaxis. ${ }^{128}$ Altogether, these results support the hypothesis that administration of anti-HPA-1a to HPA-1a-negative women after delivery of an HPA-1a-positive child may prevent immunization to HPA-1a, thereby preventing the development of FNAIT in a subsequent pregnancy. The hypothesis to prevent immunization to HPA-1a will be tested in pregnant women in an EU-supported clinical trial (www.profnait.eu).

Another potential strategy to prevent HPA-1a immunization could be to target the antigen-specific T-cell responses in these women. Little is known about how the T-cell response shapes the quality of the subsequent anti-HPA-1a antibody response and whether it could be possible to induce immune tolerance to HPA-1a by oral administration of peptides in an efficient tolerogenic formulation. Such tolerance may depend on induction of tolerogenic regulatory $\mathrm{T}$ cells or on clonal deletion or induction of clonal anergy. ${ }^{129}$

\section{Screening}

No country has yet started screening of all pregnant women to detect HPA-1a-negative pregnancies, in order to identify women at risk of alloimmunization. The implementation of such a national screening program for FNAIT has been debated in several countries. ${ }^{25,37,107}$ So far, all countries have turned down the idea because of the lack of prophylaxis or effective treatment modalities. In comparison, $\mathrm{RhD}$ typing was introduced in pregnancy screening programs 20 years before prophylaxis was started. Identification and follow-up of RhD-negative pregnancies at risk for anti-D alloimmunization have greatly reduced the risk of morbidity in newborns being exposed. Results from the Norwegian screening study showed that implementation of a screening program for HPA-1anegative pregnancies could improve clinical outcome ${ }^{25}$ and be cost-effective. ${ }^{130}$ Several other studies have also concluded that a screening and intervention program for maternal HPA-1

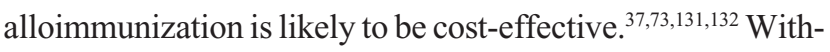
out antenatal screening, we only detect a minority of cases. ${ }^{133}$ In a recent assessment of prospective studies on screening for HPA-1a alloimmunization including 176,000 low-risk pregnancies, it was concluded that screening of all pregnancies combined with antenatal treatment may reduce mortality and morbidity associated with FNAIT but that large-scale screening studies are needed to evaluate the effect of currently used interventions. ${ }^{37}$ Introduction of antenatal screening for FNAIT was considered in relation to the revised World Health Organization screening criteria, ${ }^{134}$ and it was concluded that the screening criteria were fulfilled. ${ }^{135}$ The ongoing Polish PREVFNAIT screening study is primarily undertaken to demonstrate the feasibility of implementing antenatal HPA-1 
screening as a national routine later. In the Netherlands, the planned HPA screening In Pregnancy study aim to pave the way for the implementation of screening.

Opponents to introducing an antenatal screening program for FNAIT point out that no randomized controlled trials have been conducted to assess the possible clinical and economic benefits of screening and also that there is no consensus on how to treat pregnancies at risk of FNAIT once these pregnancies are identified. ${ }^{4,106}$ Those in favor of screening state that randomized controlled trials would be unethical to perform and that we will never gain this knowledge without first introducing screening. ${ }^{135,136}$

In the absence of antenatal screening for the detection of pregnancies at risk, previous obstetric history serves as the main basis for antenatal management protocols. ${ }^{64,119}$ ICH or severe thrombocytopenia in the previous neonate is considered useful to predict an increased risk of severe FNAIT in subsequent pregnancies. This strategy a priory excludes any management of the first FNAIT-affected pregnancy before the child is born, and it is well documented that severe FNAIT may occur in the first-born child. ${ }^{17,39}$

\section{Conclusion}

Despite large efforts, there are still considerable knowledge gaps on the pathophysiology of FNAIT. This is probably the major reason for the lack of consensus on how to manage pregnancies at risk of FNAIT. New knowledge indicating placenta as a target of maternal anti-HPA-1a antibodies in addition to fetal platelets increases clinical concern. The broader clinical impact of FNAIT together with new treatment opportunities for FNAIT strengthens the need for antenatal screening to detect pregnancies at risk of FNAIT. Without a screening program for the detection of HPA-1anegative pregnancies, the FNAIT diagnosis is almost always established after birth of a symptomatic child. With the current non-screening policy, we only detect a minority of FNAIT cases. An antibody-mediated prophylaxis to prevent HPA-1 is currently being developed and has the potential to prevent severe mortality and morbidity in newborns from FNAIT. However, it is impossible to offer an antenatal prophylaxis to HPA-1bb pregnant women without knowing who they are. Introduction of antenatal screening programs should therefore be considered.

\section{Disclosure}

$\mathrm{BS}$ and $\mathrm{AH}$ have financial relationships with Prophylix Pharma AS, a small medical company aiming to develop a FNAIT prophylaxis. HT, MTA, and TBS report no conflicts of interest in this work.

\section{References}

1. Bussel JB. Alloimmune thrombocytopenia in the fetus and newborn. Semin Thromb Hemost. 2001;27(3):245-252.

2. Castle V, Andrew M, Kelton J, Giron D, Johnston M, Carter C. Frequency and mechanism of neonatal thrombocytopenia. J Pediatr. 1986; 108(5 Pt 1):749-755.

3. Stanworth SJ, Clarke P, Watts T, et al. Prospective, observational study of outcomes in neonates with severe thrombocytopenia. Pediatrics. 2009; 124(5):e826-e834.

4. Murphy MF, Bussel JB. Advances in the management of alloimmune thrombocytopenia. Br J Haematol. 2007;136:366-378.

5. Burrows RF, Kelton JG. Fetal thrombocytopenia and its relation to maternal thrombocytopenia. $N$ Engl J Med. 1993;329:1463-1466.

6. Sainio S, Jarvenpaa AL, Renlund M, Riikonen S, Teramo K, Kekomaki R. Thrombocytopenia in term infants: a population-based study. Obstet Gynecol. 2000;95(3):441-446.

7. Kamphuis MM, Paridaans NP, Porcelijn L, Lopriore E, Oepkes D. Incidence and consequences of neonatal alloimmune thrombocytopenia: a systematic review. Pediatrics. 2014;133(4):715-721.

8. Simister NE, Story CM. Human placental Fc receptors and the transmission of antibodies from mother to fetus. J Reprod Immunol. 1997; 37(1):1-23.

9. Landau M, Rosenberg N. Molecular insight into human platelet antigens: structural and evolutionary conservation analyses offer new perspective to immunogenic disorders. Transfusion. 2010;51(3):558-569.

10. Rozman P. Platelet antigens. The role of human platelet alloantigens (HPA) in blood transfusion and transplantation. Transpl Immunol. 2002; 10(2-3):165-181.

11. Schuh AC, Watkins NA, Nguyen Q, et al. A tyrosine703serine polymorphism of CD109 defines the Gov platelet alloantigens. Blood. 2002; 99(5):1692-1698.

12. Finnson KW, Tam BY, Liu K, et al. Identification of CD109 as part of the TGF-beta receptor system in human keratinocytes. FASEB $J$. 2006;20(9):1525-1527.

13. Zdravic D, Yougbare I, Vadasz B, et al. Fetal and neonatal alloimmune thrombocytopenia. Semin Fetal Neonatal Med. 2016;21(1):19-27.

14. Shulman NR, Aster RH, Pearson HA, Hiller MC. Immunoreactions involving platelet. VI. Reactions of maternal isoantibodies responsible for neonatal purpura. Differentiation of a second platelet antigen system. J Clin Invest. 1962;41:1059-1069.

15. Van Loghem JJJ, Dorfmeijer H, Van Hart M, Schreuder F. Serological and genetical studies on a platelet antigen (Zw). Vox Sang. 1959;4(2): 161-169.

16. Davoren A, Curtis BR, Aster RH, McFarland JG. Human platelet antigen-specific alloantibodies implicated in 1162 cases of neonatal alloimmune thrombocytopenia. Transfusion. 2004;44:1220-1225.

17. Mueller-Eckhardt C, Kiefel V, Grubert A, et al. 348 cases of suspected neonatal alloimmune thrombocytopenia. Lancet. 1989;1(8634): 363-366.

18. Williamson LM, Hackett G, Rennie J, et al. The natural history of fetomaternal alloimmunization to the platelet-specific antigen HPA-1a (PlA1, Zwa) as determined by antenatal screening. Blood. 1998;92: 2280-2287.

19. Zhou J, Pop LM, Ghetie V. Hypercatabolism of IgG in mice with lupus-like syndrome. Lupus. 2005;14(6):458-466.

20. Gruel Y, Boizard B, Daffos F, Forestier F, Caen J, Wautier JL. Determination of platelet antigens and glycoproteins in the human fetus. Blood. 1986;68(2):488-492.

21. Pahal GS, Jauniaux E, Kinnon C, Thrasher AJ, Rodeck CH. Normal development of human fetal hematopoiesis between eight and seventeen weeks' gestation. Am J Obstet Gynecol. 2000;183(4):1029-1034.

22. Van den Hof MC, Nicolaides KH. Platelet count in normal, small, and anemic fetuses. Am J Obstet Gynecol. 1990;162(3):735-739.

23. Jauniaux E, Jurkovic D, Gulbis B, Liesnard C, Lees C, Campbell S. Maternofetal immunoglobulin transfer and passive immunity during the first trimester of human pregnancy. Hum Reprod. 1995;10(12):3297-3300.

24. Simister NE. Placental transport of immunoglobulin G. Vaccine. 2003; 21(24):3365-3369. 
25. Kjeldsen-Kragh J, Killie MK, Tomter G, et al. A screening and intervention program aimed to reduce mortality and serious morbidity associated with severe neonatal alloimmune thrombocytopenia. Blood. 2007;110(3):833-839.

26. L'Abbe D, Tremblay L, Filion M, et al. Alloimmunization to platelet antigen HPA-1a (PIA1) is strongly associated with both HLA-DRB3*0101 and HLA-DQB1*0201. Hum Immunol. 1992;34(2):107-114.

27. Mueller-Eckhardt C, Mueller-Eckhardt G, Willen-Ohff H, et al. Immunogenicity of and immune response to the human platelet antigen Zwa is strongly associated with HLA-B8 and DR3. Tissue Antigens. 1985; 26(1):71-76.

28. Reznikoff-Etievant MF, Muller JY, Julien F, Patereau C. An immune response gene linked to MHC in man. Tissue Antigens. 1983;22(4): 312-314.

29. Valentin N, Vergracht A, Bignon JD, et al. HLA-DRw52a is involved in alloimmunization against PL-A1 antigen. Hum Immunol. 1990; 27(2):73-79.

30. Anani Sarab G, Moss M, Barker RN, Urbaniak SJ. Naturally processed peptides spanning the HPA-1a polymorphism are efficiently generated and displayed from platelet glycoprotein by HLA-DRB3*0101-positive antigen-presenting cells. Blood. 2009;114(9):1954-1957.

31. Wu S, Maslanka K, Gorski J. An integrin polymorphism that defines reactivity with alloantibodies generates an anchor for MHC class II peptide binding: a model for unidirectional alloimmune responses. J Immunol. 1997;158(7):3221-3226.

32. Ahlen MT, Husebekk A, Killie MK, Skogen B, Stuge TB. T-cell responses associated with neonatal alloimmune thrombocytopenia: isolation of HPA-1a-specific, HLA-DRB3*0101-restricted CD4+ T cells. Blood. 2009;113(16):3838-3844.

33. Rayment R, Kooij TW, Zhang W, et al. Evidence for the specificity for platelet HPA-1a alloepitope and the presenting HLA-DR52a of diverse antigen-specific helper $\mathrm{T}$ cell clones from alloimmunized mothers. J Immunol. 2009;183(1):677-686.

34. Ahlen MTH, Husebekk A, Killie IL, Skogen B, Stuge TB. T cell responses to human platelet antigen-1a involve a unique form of indirect allorecognition. JCI Insight. 2016;1(14):PMC5033924.

35. Li C, Chen P, Vadasz B, et al. Co-stimulation with LPS or poly I:C markedly enhances the anti-platelet immune response and severity of fetal and neonatal alloimmune thrombocytopenia. Thromb Haemost. 2013; 110(6):1250-1258.

36. Mandelbaum M, Koren D, Eichelberger B, Auerbach L, Panzer S. Frequencies of maternal platelet alloantibodies and autoantibodies in suspected fetal/neonatal alloimmune thrombocytopenia, with emphasis on human platelet antigen-15 alloimmunization. Vox Sang. 2005;89: 39-43.

37. Kamphuis MM, Paridaans N, Porcelijn L, et al. Screening in pregnancy for fetal or neonatal alloimmune thrombocytopenia: systematic review. BJOG. 2010;117(11):1335-1343.

38. Dreyfus M, Kaplan C, Verdy E, Schlegel N, Durand-Zaleski I, Tchernia G. Frequency of immune thrombocytopenia in newborns: a prospective study. Immune Thrombocytopenia Working Group. Blood. 1997;89:4402-4406.

39. Ghevaert C, Campbell K, Walton J, et al. Management and outcome of 200 cases of fetomaternal alloimmune thrombocytopenia. Transfusion. 2007;47:901-910.

40. Kim HO, Jin Y, Kickler TS, Blakemore K, Kwon OH, Bray PF. Gene frequencies of the five major human platelet antigens in African American, white, and Korean populations. Transfusion. 1995;35(10):863-867.

41. Ohto H, Miura S, Ariga H, Ishii T, Fujimori K, Morita S. The natural history of maternal immunization against foetal platelet alloantigens. Transfus Med. 2004;14(6):399-408.

42. Tanaka S, Ohnoki S, Shibata H, Okubo Y, Yamaguchi H, Shibata Y. Gene frequencies of human platelet antigens on glycoprotein IIIa in Japanese. Transfusion. 1996;36(9):813-817.

43. Zhang Q, Liang LW, Gjertson DW, et al. Development of posttransplant antidonor HLA antibodies is associated with acute humoral rejection and early graft dysfunction. Transplantation. 2005;79(5):591-598.
44. Lee PC, Terasaki PI, Takemoto SK, et al. All chronic rejection failures of kidney transplants were preceded by the development of HLA antibodies. Transplantation. 2002;74(8):1192-1194.

45. Novotny VM. Prevention and management of platelet transfusion refractoriness. Vox Sanguinis. 1999;76(1):1-13.

46. King KE, Kao KJ, Bray PF, et al. The role of HLA antibodies in neonatal thrombocytopenia: a prospective study. Tissue Antigens. 1996; 47(3):206-211.

47. Morin-Papunen L, Tiilikainen A, Hartikainen-Sorri AL. Maternal HLA immunization during pregnancy: presence of anti HLA antibodies in half of multigravidous women. Med Biol. 1984;62(6): 323-325.

48. Regan L, Braude PR, Hill DP. A prospective study of the incidence, time of appearance and significance of anti-paternal lymphocytotoxic antibodies in human pregnancy. Hum Reprod. 1991;6(2): 294-298.

49. Masson E, Vidal C, Deschamps M, et al. Incidence and risk factors of anti-HLA immunization after pregnancy. Hum Immunol. 2013;74(8): 946-951.

50. Lashley EE, Meuleman T, Claas FH. Beneficial or harmful effect of antipaternal human leukocyte antibodies on pregnancy outcome? A systematic review and meta-analysis. Am J Reprod Immunol. 2013;70(2): 87-103.

51. Thude H, Schorner U, Helfricht C, Loth M, Maak B, Barz D. Neonatal alloimmune thrombocytopenia caused by human leucocyte antigen-B27 antibody. Transfus Med. 2006;16(2):143-149.

52. Starcevic M, Tomicic M, Malenica M, Zah-Matakovic V. Neonatal alloimmune thrombocytopenia caused by anti-HLA-A24 alloantibodies. Acta Paediatr. 2010;99(4):630-632.

53. Moncharmont P, Dubois V, Obegi C, et al. HLA antibodies and neonatal alloimmune thrombocytopenia. Acta Haematol. 2004;111(4): 215-220.

54. Gramatges MM, Fani P, Nadeau K, Pereira S, Jeng MR. Neonatal alloimmune thrombocytopenia and neutropenia associated with maternal human leukocyte antigen antibodies. Pediatr Blood Cancer. 2009; 53(1):97-99.

55. Saito S, Ota M, Komatsu Y, et al. Serologic analysis of three cases of neonatal alloimmune thrombocytopenia associated with HLA antibodies. Transfusion. 2003;43(7):908-917.

56. Taaning E. HLA antibodies and fetomaternal alloimmune thrombocytopenia: myth or meaningful? Transfus Med Rev. 2000;14(3): 275-280.

57. Berkowitz RL, Bussel JB, McFarland JG. Alloimmune thrombocytopenia: state of the art 2006. Am J Obstet Gynecol. 2006;195: 907-913.

58. Kiefel V, Santoso S, Weisheit M, Mueller-Eckhardt C. Monoclonal antibody-specific immobilization of platelet antigens (MAIPA): a new tool for the identification of platelet-reactive antibodies. Blood. 1987;70: 1722-1726.

59. Metcalfe P, Allen D, Chapman J, Ouwehand WH. Interlaboratory variation in the detection of clinically significant alloantibodies against human platelet alloantigens. Br J Haematol. 1997;97(1):204-207.

60. Metcalfe P, Allen D, Kekomaki R, Kaplan C, de Haas M, Ouwehand WH. An International Reference Reagent (minimum sensitivity) for the detection of anti-human platelet antigen 1a. Vox Sang. 2009;96(2): 146-152.

61. Bertrand G, Jallu V, Gouet M, et al. Quantification of human platelet antigen-1a antibodies with the monoclonal antibody immobilization of platelet antigens procedure. Transfusion. 2005;45:1319-1323.

62. Porcelijn L, Huiskes E, Comijs-van Osselen I, et al. A new bead-based human platelet antigen antibodies detection assay versus the monoclonal antibody immobilization of platelet antigens assay. Transfusion. 2014; 54(6):1486-1492.

63. Socher I, Andrei-Selmer C, Bein G, Kroll H, Santoso S. Low-avidity HPA-1 a alloantibodies in severe neonatal alloimmune thrombocytopenia are detectable with surface plasmon resonance technology. Transfusion. 2009;49(5):943-952. 
64. Radder CM, Brand A, Kanhai HH. Will it ever be possible to balance the risk of intracranial haemorrhage in fetal or neonatal alloimmune thrombocytopenia against the risk of treatment strategies to prevent it? Vox Sang. 2003;84(4):318-325.

65. Mechoulan A, Kaplan C, Muller JY, et al. Fetal alloimmune thrombocytopenia: is less invasive antenatal management safe? J Matern Fetal Neonatal Med. 2011;24(4):564-567.

66. Radder CM, Brand A, Kanhai HH. A less invasive treatment strategy to prevent intracranial hemorrhage in fetal and neonatal alloimmune thrombocytopenia. Am J Obstet Gynecol. 2001;185(3):683-688.

67. Kamphuis MM, Oepkes D. Fetal and neonatal alloimmune thrombocytopenia: prenatal interventions. Prenat Diagn. 2011;31(7):712-719.

68. Wienzek-Lischka S, Krautwurst A, Frohner V, et al. Noninvasive fetal genotyping of human platelet antigen-1a using targeted massively parallel sequencing. Transfusion. 2015;55(6 Pt 2):1538-1544.

69. van der Schoot CE, Thurik FF, Veldhuisen B, de Haas M. Noninvasive prenatal blood group and HPA-1a genotyping: the current European experience. Transfusion. 2013;53(11 Suppl 2):2834-2836.

70. Freixa L, Nogues N, Ibanez M, et al. Development and validation of non-invasive approach for fetal HPA-1a genotyping using cell-free fetal DNA present in maternal plasma. Vox Sang. 2010;99(Suppl 2):22.

71. Scheffer PG, de Haas M, van der Schoot CE. Non-invasive fetal blood typing for platelet and red cell antigens. Vox Sang. 2010; 99(Suppl 2):11.

72. Le Toriellec E, Chenet C, Kaplan C. Safe fetal platelet genotyping: new developments. Transfusion. 2013;53(8):1755-1762.

73. Turner ML, Bessos H, Fagge T, et al. Prospective epidemiologic study of the outcome and cost-effectiveness of antenatal screening to detect neonatal alloimmune thrombocytopenia due to anti-HPA-1a Transfusion. 2005;45:1945-1956.

74. Spencer JA, Burrows RF. Feto-maternal alloimmune thrombocytopenia: a literature review and statistical analysis. Aust N Z J Obstet Gynaecol. 2001;41:45-55.

75. Jocelyn LJ, Casiro OG. Neurodevelopmental outcome of term infants with intraventricular hemorrhage. Am J Dis Child. 1992;146(2):194-197.

76. Mao C, Guo J, Chituwo BM. Intraventricular haemorrhage and its prognosis, prevention and treatment in term infants. J Trop Pediatr. 1999; 45(4):237-240.

77. Tiller H, Kamphuis MM, Flodmark O, et al. Fetal intracranial haemorrhages caused by fetal and neonatal alloimmune thrombocytopenia: an observational cohort study of 43 cases from an international multicentre registry. BMJ Open. 2013;3(3):pii.e002490.

78. Kaplan C, Daffos F, Forestier F, Morel MC, Chesnel N, Tchernia G. Current trends in neonatal alloimmune thrombocytopenia: diagnosis and therapy. In: Kaplan-Gouet C, Schlegel N, Salmon C, McGregor J, editors. 206th ed. France: John Libbey Eurotext; 1991:267-278.

79. Delbos F, Bertrand G, Croisille L, Ansart-Pirenne H, Bierling P, Kaplan C. Fetal and neonatal alloimmune thrombocytopenia: predictive factors of intracranial hemorrhage. Transfusion. 2016;56(1):59-66; quiz 58

80. Winkelhorst D, Kamphuis MM, de Kloet LC, Zwaginga JJ, Oepkes D, Lopriore E. Severe bleeding complications other than intracranial hemorrhage in neonatal alloimmune thrombocytopenia: a case series and review of the literature. Transfusion. 2016;56(5):1230-1235.

81. Murphy MF, Hambley H, Nicolaides K, Waters AH. Severe fetomaternal alloimmune thrombocytopenia presenting with fetal hydrocephalus. Prenat Diagn. 1996;16(12):1152-1155.

82. Li C, Piran S, Chen P, et al. Maternal immune response to fetal platelet GPIbalpha causes frequent miscarriage in mice that can be prevented by intravenous IgG and anti-FcRn therapies. J Clin Invest. 2011;121(11): 4537-4547.

83. Ni H, Chen P, Spring CM, et al. A novel murine model of fetal and neonatal alloimmune thrombocytopenia: response to intravenous IgG therapy. Blood. 2006;107(7):2976-2983.

84. Issaka Yougbaré W-ST, Heyu Ni. Prolonged retention and activation of natural killer cells in the placenta cause miscarriage in fetal and neonatal alloimmune thrombocytopenia. Eur Symp Granul Platelet Immunobiol. 2016;23999:28.
85. Barker DJ. The developmental origins of well-being. Philos Trans $R$ Soc Lond B Biol Sci. 2004;359(1449):1359-1366.

86. Clayton PE, Cianfarani S, Czernichow P, Johannsson G, Rapaport R, Rogol A. Management of the child born small for gestational age through to adulthood: a consensus statement of the International Societies of Pediatric Endocrinology and the Growth Hormone Research Society. J Clin Endocrinol Metab. 2007;92(3): 804-810.

87. Hack M, Flannery DJ, Schluchter M, Cartar L, Borawski E, Klein N. Outcomes in young adulthood for very-low-birth-weight infants. N Engl J Med. 2002;346(3):149-157.

88. Tiller H, Kjaer KM, Husebekk A, et al. Platelet antibodies and fetal growth: maternal antibodies against fetal platelet antigen 1a are strongly associated with reduced birthweight in boys. Acta Obstetr Gynecol Scand. 2011;91:79-86.

89. Dahl J, Husebekk A, Acharya G, et al. Maternal anti-HLA class I antibodies are associated with reduced birth weight in thrombocytopenic neonates. J Reprod Immunol. 2016;113:27-34.

90. Eksteen M, Tiller H, Averina M, et al. Characterization of a human platelet antigen-1a-specific monoclonal antibody derived from a B cell from a woman alloimmunized in pregnancy. J Immunol. 2015;194(12): 5751-5760.

91. Vanderpuye OA, Labarrere CA, McIntyre JA. A vitronectin-receptorrelated molecule in human placental brush border membranes. Biochem J. 1991;280(Pt 1):9-17.

92. Zhou Y, Fisher SJ, Janatpour M, et al. Human cytotrophoblasts adopt a vascular phenotype as they differentiate. A strategy for successful endovascular invasion? J Clin Invest. 1997;99(9):2139-2151.

93. Kabir-Salmani M, Shiokawa S, Akimoto Y, et al. Alphavbeta3 integrin signaling pathway is involved in insulin-like growth factor I-stimulated human extravillous trophoblast cell migration. Endocrinology. 2003; 144(4):1620-1630.

94. Bertrand G, Martageix C, Jallu V, Vitry F, Kaplan C. Predictive value of sequential maternal anti-HPA-1a antibody concentrations for the severity of fetal alloimmune thrombocytopenia. J Thromb Haemost. 2006;4(3): 628-637.

95. Jaegtvik S, Husebekk A, Aune B, Oian P, Dahl LB, Skogen B. Neonatal alloimmune thrombocytopenia due to anti-HPA la antibodies; the level of maternal antibodies predicts the severity of thrombocytopenia in the newborn. BJOG. 2000;107:691-694.

96. Killie MK, Husebekk A, Kjeldsen-Kragh J, Skogen B. A prospective study of maternal anti-HPA 1a antibody level as a potential predictor of alloimmune thrombocytopenia in the newborn. Haematologica. 2008; 93(6):870-877.

97. Bessos H, Turner M, Urbaniak SJ. Is there a relationship between anti-HPA-1a concentration and severity of neonatal alloimmune thrombocytopenia? Immunohematol. 2005;21:102-109.

98. Ghevaert C, Campbell K, Stafford P, et al. HPA-1a antibody potency and bioactivity do not predict severity of fetomaternal alloimmune thrombocytopenia. Transfusion. 2007;47:1296-1305.

99. Bessos H, Killie MK, Seghatchian J, Skogen B, Urbaniak SJ. The relationship of anti-HPA-1a amount to severity of neonatal alloimmune thrombocytopenia - where does it stand? Transfus Apher Sci. 2009; 40(2):75-78.

100. Bertrand G, Drame M, Martageix C, Kaplan C. Prediction of the fetal status in noninvasive management of alloimmune thrombocytopenia. Blood. 2011;117(11):3209-3213.

101. Kjeldsen-Kragh J, Husebekk A, Killie MK, Skogen B. The pathophysiology of FNAIT cannot be deduced from highly selected retrospective data. Blood. 2011;118(9):2638-2639.

102. Yougbare I, Lang S, Yang H, et al. Maternal anti-platelet beta3 integrins impair angiogenesis and cause intracranial hemorrhage. J Clin Invest. 2015;125(4):1545-1556.

103. Santoso S, Wihadmadyatami H, Bakchoul T, et al. Antiendothelial alphavbeta3 antibodies are a major cause of intracranial bleeding in fetal/ neonatal alloimmune thrombocytopenia. Arterioscl Thromb Vasc Biol. 2016;36(8):1517-1524. 
104. Sonneveld ME, Natunen S, Sainio S, et al. Glycosylation pattern of anti-platelet $\mathrm{IgG}$ is stable during pregnancy and predicts clinical outcome in alloimmune thrombocytopenia. Br J Haematol. 2016; 174(2):310-320.

105. Kapur R, Kustiawan I, Vestrheim A, et al. A prominent lack of IgG1-Fc fucosylation of platelet alloantibodies in pregnancy. Blood. 2014; 123(4):471-480.

106. Bussel J. Diagnosis and management of the fetus and neonate with alloimmune thrombocytopenia. J Thromb Haemost. 2009;7(Suppl 1): 253-257.

107. Kanhai HH, Porcelijn L, Engelfriet CP, et al. Management of alloimmune thrombocytopenia. Vox Sang. 2007;93(4):370-385.

108. Tiller H, Husebekk A, Skogen B, Kjeldsen-Kragh J, Kjaer M. True risk of fetal/neonatal alloimmune thrombocytopenia in subsequent pregnancies: a prospective observational follow-up study. BJOG. 2016; 123(5):738-744

109. Vinograd CA, Bussel JB. Antenatal treatment of fetal alloimmune thrombocytopenia: a current perspective. Haematologica. 2010;95(11): 1807-1811.

110. Bussel JB, Berkowitz RL, McFarland JG, Lynch L, Chitkara U. Antenatal treatment of neonatal alloimmune thrombocytopenia. $N$ Engl J Med. 1988;319(21):1374-1378.

111. Bussel JB, Berkowitz RL, Lynch L, et al. Antenatal management of alloimmune thrombocytopenia with intravenous gamma-globulin: a randomized trial of the addition of low-dose steroid to intravenous gamma-globulin. Am J Obstet Gynecol. 1996;174:1414-1423.

112. Rayment R, Brunskill SJ, Soothill PW, Roberts DJ, Bussel JB, Murphy MF. Antenatal interventions for fetomaternal alloimmune thrombocytopenia. Cochrane Database Syst Rev. 2011;(5):CD004226.

113. Paidas MJ, Berkowitz RL, Lynch L, et al. Alloimmune thrombocytopenia: fetal and neonatal losses related to cordocentesis. Am JObstet Gynecol. 1995;172(2 Pt 1):475-479.

114. Overton TG, Duncan KR, Jolly M, Letsky E, Fisk NM. Serial aggressive platelet transfusion for fetal alloimmune thrombocytopenia: platelet dynamics and perinatal outcome. Am J Obstet Gynecol. 2002;186(4): 826-831.

115. Lakkaraja M, Berkowitz RL, Vinograd CA, et al. Omission of fetal sampling in treatment of subsequent pregnancies in fetal-neonatal alloimmune thrombocytopenia. Am J Obstet Gynecol. 2016;215(4): 471.e1-471.e9.

116. Altarescu G, Eldar-Geva T, Grisaru-Granovsky S, et al. Preimplantation genetic diagnosis for fetal neonatal alloimmune thrombocytopenia due to antihuman platelet antigen maternal antibodies. Obstet Gynecol. 2012;119(2 Pt 1):338-343.

117. Tiller H, Fedorcsak P, Skogen BR. Old tools revisited give hope new treatment option for families with a history of severe FNAIT complications. Acta Obstet Gynecol Scand. 2016;95(4):486-487.

118. Curtis BR, Bussel JB, Manco-Johnson MJ, Aster RH, McFarland JG. Fetal and neonatal alloimmune thrombocytopenia in pregnancies involving in vitro fertilization: a report of four cases. Am J Obstet Gynecol. 2005;192(2):543-547.

119. Rayment R, Brunskill SJ, Stanworth S, Soothill PW, Roberts DJ, Murphy MF. Antenatal interventions for fetomaternal alloimmune thrombocytopenia. Cochrane Database Syst Rev. 2005;(1):CD004226.

120. van den AE, Oepkes D, Brand A, Kanhai HH. Vaginal delivery for fetuses at risk of alloimmune thrombocytopenia? BJOG. 2006;113(7): 781-783.

International Journal of Women's Health

\section{Publish your work in this journal}

The International Journal of Women's Health is an international, peerreviewed open-access journal publishing original research, reports, editorials, reviews and commentaries on all aspects of women's healthcare including gynecology, obstetrics, and breast cancer. The manuscript management system is completely online and includes
121. Bassler D, Greinacher A, Okascharoen C, et al. A systematic review and survey of the management of unexpected neonatal alloimmune thrombocytopenia. Transfusion. 2008;48(1):92-98.

122. Roberts I, Stanworth S, Murray NA. Thrombocytopenia in the neonate. Blood Rev. 2008;22(4):173-186.

123. Allen D, Verjee S, Rees S, Murphy MF, Roberts DJ. Platelet transfusion in neonatal alloimmune thrombocytopenia. Blood. 2007;109(1): 388-389.

124. te Pas AB, Lopriore E, van den Akker ES, et al. Postnatal management of fetal and neonatal alloimmune thrombocytopenia: the role of matched platelet transfusion and IVIG. Eur J Pediatr. 2007;166(10): 1057-1063.

125. Blanchette VS, Johnson J, Rand M. The management of alloimmune neonatal thrombocytopenia. Baillieres Best Pract Res Clin Haematol. 2000;13:365-390.

126. Woodrow JC, ClarkeCA, Donohoe WT, etal. Prevention ofRh-haemolytic disease: a third report. Br Med J. 1965;1(5430):279-283.

127. Zipursky A, Israels LG. The pathogenesis and prevention of Rh immunization. Can Med Assoc J. 1967;97(21):1245-1257.

128. Tiller H, Killie MK, Chen P, et al. Toward a prophylaxis against fetal and neonatal alloimmune thrombocytopenia: induction of antibodymediated immune suppression and prevention of severe clinical complications in a murine model. Transfusion. 2012;52(7):1446-1457.

129. Weiner HL, da Cunha AP, Quintana F, Wu H. Oral tolerance. Immunol Rev. 2011;241(1):241-259.

130. Killie MK, Kjeldsen-Kragh J, Husebekk A, Skogen B, Olsen JA, Kristiansen IS. Cost-effectiveness of antenatal screening for neonatal alloimmune thrombocytopenia. BJOG. 2007;114:588-595.

131. Durand-Zaleski I, Schlegel N, Blum-Boisgard C, Uzan S, Dreyfus M, Kaplan C. Screening primiparous women and newborns for fetal/ neonatal alloimmune thrombocytopenia: a prospective comparison of effectiveness and costs. Immune Thrombocytopenia Working Group. Am J Perinatol. 1996;13:423-431.

132. Gafni A, Blanchette VS. Screening for neonatal alloimmune thrombocytopenia: an economic perspective. Curr Stud Hematol Blood Transfus. 1988(54):140-147.

133. Tiller H, Killie MK, Skogen B, Oian P, Husebekk A. Neonatal alloimmune thrombocytopenia in Norway: poor detection rate with nonscreening versus a general screening programme. BJOG. 2009;116(4): 594-598.

134. Andermann A, Blancquaert I, Beauchamp S, Dery V. Revisiting Wilson and Jungner in the genomic age: a review of screening criteria over the past 40 years. Bull World Health Organ. 2008;86(4):317-319.

135. Skogen B, Killie MK, Kjeldsen-Kragh J, et al. Reconsidering fetal and neonatal alloimmune thrombocytopenia with a focus on screening and prevention. Expert Rev Hematol. 2010;3(5):559-566.

136. Kjeldsen-Kragh J, Husebekk A, Killie MK, Skogen B. Is it time to include screening for neonatal alloimmune thrombocytopenia in the general antenatal health care programme? Transfus Apher Sci. 2008;38(3):183-188.

137. Heier HE, Berge LN, Hervig T, et al. Immunisering i svangerskapet. [Immunization during pregnancy]. Tidsskr Nor Laegeforen. 2009; 129(19):2016-2018

Submit your manuscript here: http://www.dovepress.com/international-journal-of-womens-health-journal

a very quick and fair peer-review system, which is all easy to use. Visit http://www.dovepress.com/testimonials.php to read real quotes from published authors. 